\title{
Gambaran kualitas hidup pasien defek kalvaria pasca bedah di RSUP Prof. Dr. R. D. Kandou Manado periode September 2014 - September 2015
}

\author{
${ }^{1}$ Kidzya C. Senduk \\ ${ }^{2}$ Maximillian Ch. Oley \\ ${ }^{2}$ Victor Pontoh
}

\author{
${ }^{1}$ Kandidat Skripsi Fakultas Kedokteran Universitas Sam Ratulangi Manado \\ ${ }^{2}$ Bagian Bedah RSUP Prof. Dr. R. D. Kandou Manado \\ Email: kidzyasenduk@gmail.co.id
}

\begin{abstract}
Nowadays, traumatic brain injury is becoming a major global problem. Decompressive craniectomy can decrease the intracranial pressure, therefore, it can improve the patients' life expectancy and quality of life. This study used questionnaires consisted of 33 questions related to life satisfaction, shapes of defects, and complaints were 8 patients with calvarial defect at Prof. Dr. R. D. Kandou Hospital Manado. Respondents from September 2014 to Sepetember 2015. The results showed that most respondents were male $(87.5 \%)$, aged 11-20 years (50\%), and lived at Banjer (37.5\%). Most patients $(62 \%)$ had moderate GCS meanwhile the GOS of patients were well recovered (87.5\%) and moderate disabilities $(12.5 \%)$. The relationships between initial GCS and GOS of patients were as follows: mild GCS who recovered (37.5\%), moderate GCS who recovered well (50\%), and moderate disability $(12.5 \%)$. Most patients $(75 \%)$ had concave calvarial defects. Patients' complaints were: tingling (12.5\%), dizziness (25\%), vertigo (12.5\%), and did not feel comfortable with their apperance (25\%); no complaints of mild or severe pain and seizures. Conclusion: In this study, the majority of patients with calvarial defects who underwent surgery at Prof. Dr. R. D. Kandou Hospital Manado had good quality of life.
\end{abstract}

Keywords: head injury, calvarial defect, quality of life

\begin{abstract}
Abstrak: Kerusakan otak traumatik merupakan masalah global utama. Kraniektomi dekompresi dapat digunakan untuk menurunkan tekanan intrakranial sehingga dapat meningkatkan harapan hidup dan kualitas hidup pasien. Penelitian ini menggunakan kuesioner terdiri dari 33 pertanyaan yang berhubungan dengan kepuasan pasien mengenai kehidupan sehari-hari, dan juga beberapa pertanyaan tambahan untuk status lokalis seperti bentuk defek dan keluhan-keluhan yang dialami. Responden ialah 8 pasien dengan defek kalvaria di RSUP Prof. Dr. R. D. Kandou Manado periode September 2014 sampai Sepetember 2015. Hasil penelitian menunjukkan karakteristik pasien dengan persentase tertinggi ialah jenis kelamin laki-laki (87,5\%), usia 11-20 tahun (50\%), dan alamat responden Banjer $(37,5 \%)$, GCS sedang $(62,5 \%)$, dan keadaan akhir pasien (GOS) pasien yang pulih dengan baik $(87,5 \%)$. Hubungan antara skor awal GCS dan keadaan akhir pasien (GOS) pada pasien dengan GCS ringan yang pulih $(37,5 \%)$, pasien dengan GCS sedang yang pulih dengan baik (50\%) sedangkan dengan disabilitas sedang $(12,5 \%)$. Menurut bentuk dari defek pasien yang terbanyak ialah defek cowong (75\%). Keluhan yang ditemukan ialah: kesemutan (12,5\%), pusing $(25 \%)$, vertigo (12,5\%), dan merasa malu dengan kondisi fisik sekarang (25\%). Tidak ditemukan keluhan nyeri ringan atau berat, maupun kejang. Simpulan: Pada studi ini, sebagian besar pasien dengan defek kalvaria yang menjalani operasi di RSUP Prof. Dr. R. D. Kandou Manado memiliki kualitas hidup yang baik.
\end{abstract}

Kata kunci: cedera kepala, defek kalvaria, kualitas hidup 
Di Amerika Serikat, kejadian cedera kepala setiap tahunnya diperkirakan mencapai 500.000 kasus. Dari jumlah tersebut, 10\% meninggal sebelum tiba di rumah sakit; yang sampai di rumah sakit $80 \%$ dikelompokkan sebagai cedera kepala ringan (CKR), $10 \%$ termasuk cedera kepala sedang (CKS), dan 10\% sisanya ialah cedera kepala berat $(\mathrm{CKB})$. Insiden cedera kepala terutama terjadi pada kelompok usia produktif 15-44 tahun. Kecelakaan lalu lintas merupakan penyebab $48-53 \%$ dari cedera kepala, 20-28\% lainnya karena jatuh dan 3-9\% lainnya disebabkan tindak kekerasan, kegiatan olahraga, dan rekreasi. ${ }^{1}$

Kasus cedera kepala paling banyak mengenai kelompok usia produktif antara 15-44 tahun dan lebih banyak pada lakilaki dibandingkan dengan perempuan. Penyebab cedera kepala terbanyak adalah kecelakaan lalu lintas dan jatuh (terutama pada anak-anak). Cedera kepala berperan pada hampir separuh dari seluruh kematian akibat trauma. $^{2}$

Kerusakan otak traumatik merupakan masalah global utama. Insiden rata-rata di perkotaan secara global berkisar dari 108 sampai 332 kasus baru yang masuk rumah sakit per 100.000 populasi per tahun. Ratarata $39 \%$ pasien dengan trauma otak berat meninggal karena cedera, dan $60 \%$ memiliki Glasgow Coma Scale (GCS) yang rendah. Di Indonesia insiden untuk cedera kepala masih belum didapatkan data pasti, ${ }^{3}$ dan dilaporkan $10-15 \%$ pasien hipertensi intrakranial yang dihasilkan oleh cedera kepala berat tidak memberikan respon yang maksimal terhadap terapi medikamentosa. Kraniektomi dekompresi dapat digunakan untuk menurunkan tekanan intrakranial sehingga dapat meningkatkan harapan hidup. $^{4}$ Kraniektomi dekompresi adalah pengangkatan tulang kranial secara luas untuk meningkatkan volume rongga kranial. $^{5}$

Disamping manfaatnya, pada kraniektomi dekompresi dapat ditemukan komplikasi yaitu ekspansi dari perdarahan yang disebabkan oleh kontusio serebri, herniasi serebral eksterna, subdural higroma, infeksi, hidrosefalus, dan epilepsi.
Yang et al. melaporkan 54 dari total 108 pasien $(50 \%)$ mengalami komplikasi akibat dekompresi kraniektomi dan 28 pasien $(25,9 \%)$ mengalami lebih dari satu komplikasi. Hal ini menyebabkan dibutuhkannya operasi kedua yaitu kranioplasti. ${ }^{6}$

\section{METODE PENELITIAN}

Jenis penelitian ini ialah deskriptif retrospektif dengan desain potong lintang. Responden ialah pasien dengan defek kalvaria di RSUP. Prof. Dr. R. D. Kandou Manado periode September 2014 sampai Sepetember 2015.

Penelitian ini menggunakan kuesioner terdiri dari 33 pertanyaan yang berhubungan dengan kepuasan pasien mengenai kehidupan mereka sehari dan juga beberapa pertanyaan tambahan untuk status lokalis seperti bentuk defek dan keluhan-keluhan yang dialami pasien. Peneliti mewawancarai 8 pasien dengan defek kalvaria secara langsung yang berhasil ditemukan dari alamat dan nomor telepon dalam catatan rekam medik pasien

\section{HASIL PENELITIAN DAN BAHASAN}

Tabel 1 menunjukkan gambaran usia pasien dengan persentase tertinggi pada jenis kelamin laki-laki (87,5\%), usia 11-20 tahun $(50 \%)$; dan alamat responden Banjer $(37,5 \%)$ (Tabel 1). Hal ini sesuai dengan tingginya angka kecelakaan bermotor yang paling banyak melibatkan jenis kelamin laki-laki dan usia remaja. $^{2}$

Prevelansi cedera kepala di Indonesia sangat tinggi dimana Indonesia berada di peringkat ke 5 dunia. Setiap jam setidaknya 12 kasus kecelakaan terjadi diseluruh Indonesia dengan kematian 69 orang per harinya. Pada tahun 2013 terdapat 101.037 kecelakaan lalu lintas yang merenggut nyawa 25.157 orang sedangkan kerugian yang ditimbulkan mencapai lebih dari 254 milyar rupiah. Sulawesi Utara berada di peringkat 14 nasional dengan tingkat kecelakaan $47,2 \%$ yang didominasi oleh kecelakaan kendaraan bermotor. Menurut Riset Kesehatan Dasar 2013, kecelakaan kendaraan bermotor paling sering terjadi pada laki-laki $(44,6 \%)$ dengan kelompok usia $15-24$ tahun $(64,7 \%)$. 
Tabel 1. Karakteristik umum responden

\begin{tabular}{llcc}
\hline & & Frekuensi & $(\%)$ \\
\hline Jenis kelamin & Laki-laki & 7 & $87,5 \%$ \\
& Perempuan & 1 & $12,5 \%$ \\
& Jumlah & 8 & $100 \%$ \\
\hline Usia & $<10$ tahun & 1 & $12,5 \%$ \\
& $11-20$ tahun & 4 & $50 \%$ \\
& $21-30$ tahun & 3 & $37,5 \%$ \\
& $31-40$ & 0 & $0 \%$ \\
& $41-50$ & 0 & $0 \%$ \\
& $51-60$ & 0 & $0 \%$ \\
& Al-70 & 0 & $0 \%$ \\
& $>70$ & 0 & $0 \%$ \\
& Jumlah & 8 & $100 \%$ \\
\hline & Malalayang & 1 & $12,5 \%$ \\
& Banjer & 3 & $37,5 \%$ \\
& Molas & 1 & $12,5 \%$ \\
& Tongkaina & 1 & $12,5 \%$ \\
& Perkamil & 1 & $12,5 \%$ \\
& Karombasan & 1 & $12,5 \%$ \\
& Jumlah & 8 & $100 \%$ \\
\hline
\end{tabular}

Tabel 2 menunjukkan keadaan awal pasien (GCS) paling banyak ialah cedera kepala sedang sebanyak 5 pasien $(62,5 \%)$. Dalam hal pertimbangan GCS saat masuk sebagai prediktor prognosis, masalah yang dihadapi ialah seberapa tepat penilain GCS saat awal masuk bahkan prognosisnya tidak dapat diprediksi secara akurat walaupun GCS saat masuk rendah. Beberapa penelitian menunjukkan bahwa GCS awal masuk yang tinggi mempunyai prognosis lebih baik dibandingkan GCS awal masuk yang rendah. Terdapat beberapa faktor yang turut memengaruhi mortalitas penderita cedera kepala diantaranya ialah jedah waktu cedera dengan operasi; semakin cepat penderita cedera kepala dioperasi maka sebagian besar mempunyai prognosis baik. ${ }^{8}$

Tabel 2. Distribusi keadaan awal pasien (GCS)

\begin{tabular}{lcc}
\hline $\begin{array}{c}\text { Keadaan awal } \\
\text { (GCS) }\end{array}$ & Frekuensi & $\mathbf{( \% )}$ \\
\hline Ringan (14-15) & 3 & $37,5 \%$ \\
Sedang (9-13) & 5 & $62,5 \%$ \\
Berat (3-8) & 0 & $0 \%$ \\
Jumlah & 8 & $100 \%$ \\
\hline
\end{tabular}

Tabel 3 mengenai keadaan akhir pasien (GOS) yang menunjukkan bahwa tidak ditemukan pasien yang meninggal, dalam keadaan koma vegetatif, dan yang dengan disabilitas berat. Pasien yang pulih dengan baik sebanyak 7 pasien $(87,5 \%)$ sedangkan yang dengan disabilitas sedang sebanyak 1 pasien $(12,5 \%)$.

Tabel 3. Distribusi pasien cedera kepala berdasarkan keadaan akhir pasien (GOS)

\begin{tabular}{clcc} 
Nilai & $\begin{array}{l}\text { Keadaan akhir } \\
\text { (GOS) }\end{array}$ & Frekuensi & $(\%)$ \\
\hline 1 & Meninggal & 0 & $0 \%$ \\
2 & Keadaan vegetatif & 0 & $0 \%$ \\
3 & Disabilitas berat & 0 & $0 \%$ \\
4 & Disabilitas sedang & 1 & $12,5 \%$ \\
5 & Pemulihan baik & 7 & $87,5 \%$ \\
& Jumlah & 8 & $100 \%$
\end{tabular}

Tabel 4 menunjukkan hubungan antara skor awal GCS dan keadaan akhir pasien (GOS). Pasien dengan GCS ringan yang pulih sebanyak 3 pasien (37,5\%) dan pasien dengan GCS sedang pulih dengan baik 4 pasien $(50 \%)$ sedangkan dengan disabilitas sedang 1 pasien $(12,5 \%)$. 
Senduk, Oley, Pontoh: Gambaran kualitas hidup...

Tabel 4. Hubungan antara skor awal GCS dan keadaan akhir pasien (GOS)

\begin{tabular}{ccccccc}
\hline \multirow{2}{*}{$\begin{array}{c}\text { Skor } \\
\text { awal }\end{array}$} & \multicolumn{5}{c}{ GOS } \\
\cline { 2 - 7 } & Meninggal & $\begin{array}{c}\text { Keadaan } \\
\text { vegetatif }\end{array}$ & $\begin{array}{c}\text { Disabilitas } \\
\text { berat }\end{array}$ & $\begin{array}{c}\text { Disabilitas } \\
\text { ringan }\end{array}$ & $\begin{array}{c}\text { Pulih } \\
\text { dengan baik }\end{array}$ & Total \\
GCS & & $0(0 \%)$ & $0(0 \%)$ & $0(0 \%)$ & $3(37,5)$ & $3(37,5 \%)$ \\
Ringan & $0(0 \%)$ & $0(0 \%)$ & $0(0 \%)$ & $1(12,5 \%)$ & $4(50 \%)$ & $5(62,5 \%)$ \\
Sedang & $0(0 \%)$ & $0(0 \%)$ & $0(0 \%)$ & $0(0 \%)$ & $0(0 \%)$ & $0(0 \%)$ \\
Berat & $0(0 \%)$ & $0(0 \%)$ & $0(0 \%)$ & $7(87,5 \%)$ & $8(100 \%)$ \\
Total & $0(0 \%)$ & $0(0 \%)$ & $0(0 \%)$ & $1(12,5 \%)$ & $7(00)$ \\
\hline
\end{tabular}

Tabulasi silang antara GCS dan GOS menunjukkan bahwa pasien dengan GCS rendah berhubungan dengan tingginya kecacatan yang dialami.

Kuesioner penilaian kualitas hidup terdiri 33 pertanyaan yang disusun berdasarkan Ferrans \& Powers Quality of Life Index, meliputi berbagai aspek, yaitu: fungsi sosial, fisik, nyeri, kesehatan mental, fungsi mental, serta kesehatan secara umum. ${ }^{9}$ Dalam penelitian ini diperoleh 8 pasien $(100 \%)$ merasa puas dengan kondisi pasca operasi (Tabel 5)

Tabel 5. Karakteristik responden tentang kepuasan

\begin{tabular}{ccc}
\hline Kepuasan & Frekuensi & $(\boldsymbol{\%})$ \\
\hline Puas & 8 & $100 \%$ \\
Tidak Puas & 0 & $0 \%$ \\
Jumlah & 8 & $100 \%$ \\
\hline
\end{tabular}

Gangguan mental dan fungsional pasca trauma akan memengaruhi pasien di kemudian hari. Persepsi individu dalam melihat posisi mereka dalam kehidupan, budaya dan nilai yang mereka jalani dan dalam hubungannya dengan tujuan dan harapan serta kekhawatiran mereka. Konsep ini akan mulai mempengaruhi individu dengan cara yang kompleks dipengaruhi oleh kesehatan fisik, keadaan psikologi, tingkat kemandirian, hubungan sosial, dan hubungan mereka dengan lingkungan mereka. Semua ini mempersulit pasien untuk normal dalam masyarakat. Rehabilitasi pasien dengan cedera kepala sangat penting untuk mengembalikan fungsi fisik dan mental penderita agar mampu hidup secara normal dalam kehidupan prbadi maupun kehidupan sosial. $^{8}$

Tabel 6 menunjukan bentuk defek dari pasien dimana. Terdapat 6 pasien $(75 \%)$ memiliki defek berbentuk cowong sedangkan 2 pasien $(25 \%)$ memiliki defek menonjol.

Tabel 6. Karakteristik bentuk defek

\begin{tabular}{lcc}
\hline Bentuk defek & Frekuensi & \% \\
\hline Cowong & 6 & $75 \%$ \\
Timbul & 2 & $25 \%$ \\
\hline Jumlah & 8 & $100 \%$ \\
\hline
\end{tabular}

Tabel 7 memperlihatkan karakteristik pasien dengan keluhan-keluhan berupa kesemutan $(12,5 \%)$, pusing (25\%), vertigo $(12,5 \%)$, dan malu dengan kondisi fisik (25\%). Keluhan nyeri ringan dan berat serta kejang tidak ditemukan. Pasien dengan keluhan dan yang merasa malu dengan kondisi fisiknya memerlukan pengobatan terhadap gejala yang timbul, edukasi serta dukungan psikologi, spiritual, sosial, dan dukungan dari keluarga. ${ }^{8}$

\section{SIMPULAN}

Berdasarkan hasil penelitian kualitas hidup pada pasien dengan defek kalvaria disimpulkan bahwa trauma kepala lebih sering terjadi pada jenis kelamin laki-laki, GCS yang rendah berhubungan dengan tingginya kecacatan yang dialami, dan responden merasa puas dengan kehidupan pasca bedah dan memiliki kualitas hidup yang baik. 
Tabel 7. Karakteristik keluhan pasien

\begin{tabular}{lcc}
\hline Keluhan & Frekuensi & \% \\
\hline Kesemutan & & \\
Ada & 1 & $12,5 \%$ \\
Tidak & 7 & $87,5 \%$ \\
\hline Jumlah & 8 & $100 \%$ \\
\hline Nyeri & & \\
Ringan & & \\
Ada & 0 & $0 \%$ \\
Tidak & 8 & $100 \%$ \\
\hline Jumlah & 8 & $100 \%$ \\
\hline Nyeri Berat & & \\
Ada & 0 & $0 \%$ \\
Tidak & 8 & $100 \%$ \\
\hline Jumlah & 8 & $100 \%$ \\
\hline Pusing & & \\
Ada & 2 & $25 \%$ \\
Tidak & 6 & $75 \%$ \\
\hline Jumlah & 8 & $100 \%$ \\
\hline Kejang & & \\
Ada & 0 & $0 \%$ \\
Tidak & 8 & $100 \%$ \\
\hline Jumlah & 8 & $100 \%$ \\
\hline Vertigo & & \\
Ada & 1 & $12.5 \%$ \\
Tidak & 7 & $87,5 \%$ \\
\hline Jumlah & 8 & $100 \%$ \\
\hline Malu & & \\
dengan fisik & & \\
Ya & 2 & $25 \%$ \\
Tidak & 6 & $75 \%$ \\
\hline Jumlah & 8 & $100 \%$ \\
\hline & &
\end{tabular}

DAFTAR PUSTAKA

1. Turner DA. Neurological evaluation of a patient with head trauma. In:
Neurosurgery (2nd ed). New York: McGraw Hill, 1996.

2. Satyanegara, Arifin Z, Hasan RY, Abubakar S, Yuliatri N, Prabowo H, et al. Ilmu Bedah Saraf. Jakarta: Gramedia, 2010; p. 27, 30, 341, 479.

3. Rosenfeld JV, Maas AL, Bragge P, Morganti-Kossman MC, Manley GT, Gruen RL. Early management of severe traumatic brain injury. Lancet. 2012;380(9847):1088-95

4. Ban SP, Son YJ, Yang HJ, Chung YS, Han DH. Analysis of complications following decompressive craniectomy for traumatic brain injury. J Korean Neurosurg Soc. 2010;48:244-50.

5. Hutchinson $P$, Timofeev I, Kirkpatrick $P$. Surgery for brain edema. Neurosurg Focus. 2007;22(5):E14.

6. Margules A, Jallo J. Complication of decompressive craniectomy. JHN Journal Trauma. 2010:9-12. Philadelphia: Thomas Jefferson University.

7. RISKESDAS. Riset kesehatan dasar. Badan Penelitian dan Pengembangan Kesehatan Kementrian Kesehatan RI tahun 2013.

8. Zwingly $P$, Oley MCh, Limpeleh HP. Gambaran kualitas hidup pasien cedera kepala periode Januari 2012Desember 2013 di RSUP Prof. Dr. R. D Kandou Manado. eCl. 2015;3(1):563-67.

9. Kimura M, Da Silva JV. Ferrans and Powers quality of life index. Rev Esc Enferm USP. 2009;43(Spe):1096102. 